\title{
Genetic Diversity Analysis in Ashwagandha [Withania somnifera (L.) Dunal] Genotypes
}

\author{
Surya Chauhan*, Arunabh Joshi, G. Rajamani and Devendra Jain \\ Department of Molecular Biology and Biotechnology, Rajasthan College of Agriculture, \\ Maharana Pratap University of Agriculture and Technology, \\ Udaipur-313 001, Rajasthan, India \\ *Corresponding author
}

\section{Keywords}

Withania somnifera, $\mathrm{D}^{2}$ statistics, Cluster analysis, Genetic diversity, Inter and intra cluster

Article Info

Accepted:

12 December 2017

Available Online:

10 January 2018

\section{A B S T R A C T}

Genetic diversity among 25 Ashwagandha (Withania somnifera) accessions of different geographic origin was assessed using Mahalanobis $\mathrm{D}^{2}$ statistics. Observations revealed significant genotypic differences and accordingly genotypes were classified into five clusters. Cluster II was the largest comprising about 12 genotypes or $48 \%$ of the genotypes belonged to this cluster followed by cluster V and IV which contained 6 and 4 genotypes. The clusters I and III each had only 2 and 1 genotype, respectively. The highest intercluster distance was noted between clusters I and V (33.37) followed by cluster I and IV (27.41), III and I (26.66), I and II (25.84), V and III (22.14). The genotypes grouped in these clusters are found to be diverse. The least (10.83) inter-cluster distance was observed for cluster II and V followed by (12.21) inter cluster distance between II and IV, thereby indicating their genetic relatedness. The average intra-cluster distance between the genotypes was maximum (103.81) for the cluster II followed in descending order by cluster V (50.89), IV (28.83), I (13.85) and III (1.0), respectively. Cluster V had 6 genotypes over average values for number of primary branches per plant, days to $75 \%$ maturity, dry root yield per plant, total alkaloid content and total starch content and showed above average values for number of primary branches per plant, days to $75 \%$ maturity, dry root yield per plant, total alkaloid content and total starch content indicating their good potential for crop productivity. Thus, hybridization among these genotypes can generate desirable transgressive segregants.

\section{Introduction}

Withania somnifera also known as Ashwagandha, Indian ginseng, poison gooseberry or winter cherry belongs to family Solanaceae and is a cross pollinated crop with chromosome number of $2 \mathrm{n}=48$ (Nigam and Kandalkar, 1995) and is one of the important medicinal plants (Mir et al., 2013). It is a hardy and drought tolerant perennial shrub and grows naturally under subtropical dry climate (with an average rain fall of 600-750 mm) in well drained, sandy loam or light red soils that have a $\mathrm{pH}$ of 7.5 to 8.0. The genus Withania comprises of 23 species among which only two (Withania somnifera and Withania coagulans) are reported from India. It is a native herb of North-Western and Central 
India as well as Mediterranean region of North Africa. It grows wild in north western regions such as Gujarat, Rajasthan, Madhya Pradesh, Uttar Pradesh, Punjab, Himachal Pradesh and Jammu. Withania coagulans (L) is a wildgrowing species of Withania. It is a late kharif crop and grows under dry climate or requires less irrigation for plant growth under rain fed cultivation. It is grown mostly on marginal lands of Neemuch and Mandsaur districts of Madhya Pradesh and Kota, Jhalawar, Pratapgarh, Chittorgarh and Baran districts of Rajasthan. The main active constituents are alkaloids and steroidal lactones. The important chemical constituents (Withanolides) are present in roots, leaf and berries. The dried roots of ashwagandha have been employed as valuable source of active medicinal ingredients in Indian traditional systems of medicine: Ayurveda, Siddha and Unani. It forms essential constituent or whole of 100 medicinal formulations of traditional pharmacies like Ayurveda, Unani and Sidha (Tuli and Sangwan, 2009). The roots of the plant are categorized as rasayanas, functions as a tonic for vitality and longevity (Singh et al., 2010) and have been used as antioxidant, adaptogen, aphrodisiac, liver tonic, antiinflammatory agent, astringent and more recently to treat ulcers, bacterial infections, venom toxins, senile dementia, hiccups, bronchitis, rheumatism, dropsy, several female disorders, stomach and lung inflammation, skin diseases, asthma, emaciation, insomnia, neurological disorders, Parkinson's disease. The medicinal utility of roots is due to presence of number of alkaloids. The total alkaloid content in the roots varied from 0.16 to 0.66 per cent (Biennial Progress Report, 2006-2008). The main alkaloids are withanolides, sominiferine, sominiferinine, somnine, withananine, pseudo withanolides, withananinine and withasomnine (Covello and Ciampa, 1960). The roots of ashwagandha have properties similar to ginseng roots, used for the maintenance and restoration of health; hence it is also known as Indian ginseng (Singh and Kumar, 2010).

For morphological characterization, $\mathrm{D}^{2}$ statistics is important for analysis and assessment among genotypes of ashwagandha and also in other plant species for genetic diversity studies. The $\mathrm{D}^{2}$ statistics and clustering suggested helps to search genetically diverse types for hybridization programme. The inter-cluster distance is higher than the intra-cluster, indicating the wide genetic diversity among the genotypes. The greater the distance between clusters, wider the genetic diversity between the genotype. Highly divergent genotypes would produce broad spectrum variability in subsequent generations enabling further selection and improvement (Singh, 2014). The hybrids developed from the selected genotypes within the limit of compatibility of these clusters may produce desirable trasgressive segregants of higher magnitude of heterosis (Singh et al., 2014 and Joshi et al., 2015).

Limited work has been done for improvement of this important medicinal plant and so results of the present study will help in analysis of genetic diversity based on morphological markers, supplemented by other genetic markers of the coming decade. This will be of great significance for future crop improvement programmes.

\section{Materials and Methods}

The experimental material consisted of twenty five genotypes of ashwagandha; the seeds of which were sown in randomized block design, in three replications, at the research farm of Rajasthan College of Agriculture, Maharana Pratap University of Agriculture and Technology Udaipur during Kharif 2013-14. Source and details of plant genetic material are given in Table 1 . 
Seeds of twenty five genotypes were planted with a row-to-row spacing of $30 \mathrm{~cm}$ and a 10 cm plant-to-plant distance. Fertilizers were applied (@15 kg N/ha and 15 kg $\mathrm{P}_{2} \mathrm{O}_{5} / \mathrm{ha}$ ) at the time of sowing. All the recommended agronomical practices and plant protection measures were adopted to raise a healthy crop canopy.

At maturity, five competitive plants were randomly selected from every replication of each genotype to record observations, except for days to $75 \%$ flowering and $75 \%$ days to maturity observations that were recorded on plot basis. The experimental material was evaluated for seven characters viz., plant height, days to $75 \%$ flowering, days to $75 \%$ maturity, dry root yield, number of primary branches per plant, root diameter and root length. The statistical analysis for quantitative characters was done on the basis of average values.

The data on morphological traits in the three replications was subjected to analysis of variance based on the method described by Panse and Sukhatme (1985) for individual characters. The data with replications were subjected to genetic divergence analysis using Mahalanobis's $\mathrm{D}^{2}$ - statistics (Mahalanobis, 1936). In the present investigation, based on data of morphological and quality characters, grouping of all 25 genotypes of ashwagandha was done using Ward's minimum variance method. Intra- and inter-cluster distances generated were used to describe the relationship among the genotypes.

\section{Results and Discussion}

The mean values for performance and the origin of the 25 genotypes of ashwagandha are given in Table 1. Analysis of variance revealed highly significant difference for all characters studied indicating thereby considerable genetic variability among the genotypes. Analysis of variance revealed highly significant differences for all characters studied, thus indicating considerable genetic variability among the genotypes. The extent of variability on the morphological characters were: plant height $(28-50 \mathrm{~cm})$, number of primary branches/plant (2-4), days to $75 \%$ flowering (79-113), days to $75 \%$ maturity (147-164), root length $(12-22.4 \mathrm{~cm})$, root diameter $(0.86-1.45 \mathrm{~cm})$, dry root yield (1.21$4.59 \mathrm{~g} / \mathrm{plant})$, total alkaloid content (0.08$0.96 \%)$, total starch content (4.4-15.7\%). The variation among the individual genotypes is based on environmental/genetic effects (Rao, 1952). The twenty five genotypes from different regions of the country grown at a single location were subjected to same environmental conditions. Therefore, observed variations could be largely genetically based. The dry root yield/plant was maximum in UWS-134 followed by UWS-67 and UWS-13 $(4.59,4.58$ and $4.57 \mathrm{~g})$ respectively. The evaluation of these ashwagandha germplasm showed a large variation in the quantitative traits between the genotypes (Table 1).

The average mean squares from the ANOVA for different characters (Table 2) revealed that the mean squares due to genotypes were highly significant for all the characters observed, indicating the occurrence of significant genetic variability in the material.

The study provides the scope for selection and further subsequent utility of the genotypes in future crop improvement programmes. Hence the material appeared to be appropriate for further genetic analyses. Similarly, Singh et al., (2014) revealed significant differences among different ashwagandha genotypes for all the traits studied.

Grouping the 25 genotypes of ashwagandha into 5 clusters by using $\mathrm{D}^{2}$ statistics revealed that the genotypes within a cluster had a small or low $\mathrm{D}^{2}$ values among themselves than those 
placed in other clusters. Table 3 shows the cluster profile of these 25 genotypes followed by Euclidean ${ }^{2}$ Distance values as shown in Figure 1.

Cluster II was the largest comprising 12 genotypes or $48 \%$ of the genotypes belonged to this cluster. Clusters V and IV followed next, containing 6 and 4 genotypes, while the clusters I and III each had only 2 and 1 genotype, respectively. Similarly Singh et al., (2014) reported grouping of 21 genotypes of ashwagandha into 5 clusters. Misra et al.,
(1998) grouped genotypes of ashwagandha into 8 clusters. Fifty-five diverse genotypes of ashwagandha were grouped into ten different clusters by Jain et al., (2007). Gupta et al., (2011) carried out a genetic divergence study in 75 genotypes of ashwagandha and grouped them into fourteen clusters using Tocher's method. Kumar et al., (2007) and Singh et al., (2014) carried out genetic divergence studies in 25 accessions of ashwagandha and grouped them into 5 clusters by $\mathrm{D}^{2}$ statistics (Table 4). Joshi et al., (2015) report the grouping of ashwagandha genotypes into 6 clusters.

Table.1 Details of twenty five genotypes of ashwagandha used in present investigation

\begin{tabular}{|c|}
\hline Genotypes \\
\hline UWS-10 \\
\hline UWS-11 \\
\hline UWS-13 \\
\hline UWS-15 \\
\hline UWS-22 \\
\hline UWS-23 \\
\hline UWS-28 \\
\hline UWS-32 \\
\hline UWS-35 \\
\hline UWS-37 \\
\hline UWS-56 \\
\hline UWS-59 \\
\hline UWS-60 \\
\hline UWS-67 \\
\hline UWS-77 \\
\hline UWS-92 \\
\hline UWS-93 \\
\hline UWS-98 \\
\hline UWS-111 \\
\hline UWS-134 \\
\hline AWS21 \\
\hline HWS-08-14 \\
\hline RVA-100 \\
\hline JA-20 \\
\hline JA-134 \\
\hline \\
\hline
\end{tabular}

\begin{tabular}{|c|}
\hline Source \\
\hline $\begin{array}{l}\text { Germplasm Collection AICRP in } \\
\text { MAP\&B, Udaipur }\end{array}$ \\
\hline -do- \\
\hline -do- \\
\hline -do- \\
\hline -do- \\
\hline -do- \\
\hline -do- \\
\hline -do- \\
\hline -do- \\
\hline -do- \\
\hline -do- \\
\hline -do- \\
\hline -do- \\
\hline -do- \\
\hline -do- \\
\hline -do- \\
\hline -do- \\
\hline -do- \\
\hline -do- \\
\hline -do- \\
\hline AAU, Anand \\
\hline CCSHAU, Hisar \\
\hline RVSKVV, Mandsaur \\
\hline -do- \\
\hline -do- \\
\hline
\end{tabular}


Table.2 Mean performance of different genotypes for various characters in W. somnifera L. Dunal

\begin{tabular}{|c|c|c|c|c|c|c|c|c|c|c|c|}
\hline Genotypes & Code & $\begin{array}{l}\text { Plant } \\
\text { Height }(\mathrm{cm})\end{array}$ & $\begin{array}{l}\text { No. of primary } \\
\text { branches/ plant }\end{array}$ & $\begin{array}{l}\text { Days to } 75 \% \\
\text { flowering }\end{array}$ & $\begin{array}{l}\text { Days to } 75 \% \\
\text { maturity }\end{array}$ & $\begin{array}{l}\text { Root length } \\
(\mathrm{cm})\end{array}$ & $\begin{array}{l}\text { Root Diameter } \\
(\mathrm{cm})\end{array}$ & $\begin{array}{l}\text { Dry Root Yield } \\
\text { (g)/plant }\end{array}$ & $\begin{array}{l}\text { Total Alkaloid } \\
\text { Content }(\%)\end{array}$ & $\begin{array}{l}\text { Total starch } \\
\text { content }(\%)\end{array}$ & $\begin{array}{l}\text { Total crude } \\
\text { fibre content } \\
(\%)\end{array}$ \\
\hline UWS-10 & 1 & 41 & 2.3 & 111 & 150 & 16.8 & 1.25 & 1.53 & 0.17 & 8.9 & 31.2 \\
\hline UWS-11 & 2 & 32 & 2 & 91 & 156 & 18 & .10 & 4.17 & 0.51 & 11.3 & 32 \\
\hline UWS-13 & 3 & 41 & 4 & 92 & 158 & 17 & .12 & 4.57 & 0.27 & 14.9 & 33 \\
\hline UWS-15 & 4 & 44 & 3 & 94 & 151 & 19 & .13 & 2.5 & 0.89 & 12.4 & 22.2 \\
\hline UWS-22 & 5 & 41 & 2 & 84 & 164 & 16.2 & .95 & 4.17 & 0.9 & 5.8 & 28.7 \\
\hline UWS-23 & 6 & 39 & 2.7 & 93 & 148 & 15.7 & .91 & 3.05 & 0.67 & 14.9 & 27.6 \\
\hline UWS-28 & 7 & 43 & 3 & 85 & 152 & 17 & 1.06 & 2.08 & 0.17 & 15 & 22.8 \\
\hline UWS-32 & 8 & 47 & 2 & 89 & 150 & 16.5 & 1.45 & 4.17 & 0.42 & 4.4 & 35.8 \\
\hline UWS-35 & 9 & 42 & 2 & 84 & 152 & 16 & .10 & 3.33 & 0.28 & 10.5 & 31.8 \\
\hline UWS-37 & 10 & 50 & 3 & 79 & 148 & 21 & .96 & 2.5 & 0.08 & 13.6 & 26 \\
\hline UWS-56 & 11 & 40 & 2 & 89 & 155 & 16 & 1.15 & 3.33 & 0.71 & 12.9 & 28.1 \\
\hline UWS-59 & 12 & 38 & 2 & 89 & 150 & 21 & .95 & 2.92 & 0.96 & 15.7 & 29.9 \\
\hline UWS-60 & 13 & 43 & 3 & 86 & 157 & 13 & 1.21 & 4.17 & 0.5 & 10.7 & 29.8 \\
\hline UWS-67 & 14 & 28 & 2 & 87 & 148 & 12 & .92 & 4.58 & 0.16 & 13.7 & 34.3 \\
\hline UWS-77 & 15 & 32 & 3 & 88 & 149 & 17 & .95 & 2.5 & 0.42 & 10.3 & 23.3 \\
\hline UWS-92 & 16 & 36 & 3 & 79 & 155 & 14.5 & 1.22 & 2.08 & 0.18 & 13 & 18.7 \\
\hline UWS-93 & 17 & 32 & 3 & 80 & 154 & 12 & .96 & 2.5 & 0.18 & 14.6 & 22.3 \\
\hline UWS-98 & 18 & 33 & 4 & 79 & 164 & 20 & .86 & 2.5 & 0.7 & 15.1 & 21 \\
\hline UWS-111 & 19 & 49 & 2 & 79 & 157 & 16 & 1.3 & 3.33 & 0.5 & 12.1 & 33.8 \\
\hline UWS-134 & 20 & 38 & 2 & 78 & 158 & 12 & .92 & 4.59 & 0.69 & 14.9 & 30.6 \\
\hline AWS2B & 21 & 43.8 & 3.3 & 113 & 155 & 13.6 & 1.22 & 1.46 & 0.81 & 10.7 & 19.3 \\
\hline HWS-8-14 & 22 & 49 & 3 & 85 & 154 & 22.4 & 1.04 & 1.21 & 0.3 & 12.5 & 19.3 \\
\hline RVA- 100 & 23 & 39.3 & 3 & 89 & 153 & 15 & 1.11 & 2.92 & 0.28 & 5.5 & 26.2 \\
\hline JA-20 & 24 & 38 & 2 & 80 & 147 & 16.2 & 1.27 & 3.75 & 0.54 & 13.4 & 31.5 \\
\hline JA-134 & 25 & 33.3 & 3 & 80 & 155 & 15.1 & 1.11 & 3.33 & 0.61 & 15.7 & 30.3 \\
\hline Mean & & 39.54 & 2.65 & 87.39 & 153.50 & 16.36 & 1.087 & 3.09 & 0.48 & 12.22 & 27.4 \\
\hline Range & & $28-50$ & $2-4$ & $79-113$ & $147-164$ & $12-22.4$ & $.86-1.45$ & $1.21-4.59$ & $0.08-0.96$ & 4.4-15.7 & $18.7-35.8$ \\
\hline Error & & 0.40 & 0.11 & 0.57 & 0.52 & 0.43 & 0.52 & 0.03 & 0.00 & 0.53 & 0.28 \\
\hline CD at $5 \%$ & & 1.13 & 0.31 & 1.63 & 1.49 & 1.22 & 1.49 & 0.08 & 0.01 & 1.50 & 0.79 \\
\hline $\mathrm{CV}$ & & 1.73 & 7.03 & 1.14 & 0.59 & 4.55 & 8.33 & 1.49 & 1.63 & 7.49 & 5.07 \\
\hline
\end{tabular}


Table.3 ANOVA for the 10 chosen morphological characters in 25 genotypes of $W$. somnifera

\begin{tabular}{|c|c|c|c|c|}
\hline S.No. & Characters & \multicolumn{3}{|c|}{ Source of variation } \\
\hline & \multirow[t]{2}{*}{ Degree of freedom } & Replication & Treatment & Error \\
\hline & & 2 & 24 & 48 \\
\hline 1 & Plant height & 13.72 & $95.55 * *$ & 0.47 \\
\hline 2 & $\begin{array}{l}\text { No. of Primary } \\
\text { branches/plant }\end{array}$ & 0.02 & $1.21 * *$ & 0.03 \\
\hline 3 & Days to $75 \%$ flowering & 0.69 & $242.38 * *$ & 0.99 \\
\hline 4 & Days to $75 \%$ maturity & 5.32 & $62.77 * *$ & 0.82 \\
\hline 5 & Root length & 11.68 & $23.45 * *$ & 0.56 \\
\hline 6 & Root Diameter & 5.32 & $6.67 * *$ & 0.82 \\
\hline 7 & Dry Root yield /plant & 0.0012 & $3.05^{* *}$ & 0.0021 \\
\hline 8 & Total alkaloid content & 0.01 & $0.21 * *$ & 0.0001 \\
\hline 9 & Total starch content & 3.88 & $30.79 * *$ & 0.84 \\
\hline 10 & $\begin{array}{l}\text { Total crude fibre } \\
\text { content }\end{array}$ & 4.12 & $77.87 * *$ & 0.87 \\
\hline
\end{tabular}

$\mathrm{df}=$ degree of freedom

$*, * *=$ Significant at $5 \%$ and $1 \%$ probability level, respectively

Table.4 Grouping of 25 genotypes of $W$. somnifera (L.) Dunal into various clusters on the basis of $\mathrm{D}^{2}$ statistics

\begin{tabular}{|c|c|c|}
\hline Cluster & $\begin{array}{l}\text { Number } \\
\text { genotypes }\end{array}$ & Genotypes \\
\hline $\mathbf{I}$ & 2 & UWS 10, AWS2B \\
\hline II & 12 & $\begin{array}{l}\text { UWS } 11 \text {, UWS } 13 \text {, UWS } 23 \text {, UWS } 35 \text {, UWS } 56 \text {, } \\
\text { UWS } 59 \text {, UWS } 60 \text {, UWS } 67 \text {, UWS } 77 \text {, UWS } 111 \text {, } \\
\text { RVA } 100, \text { JA-20 }\end{array}$ \\
\hline III & 1 & UWS 32 \\
\hline IV & 4 & UWS 15, UWS 28, UWS 37, HWS-8-14 \\
\hline$\overline{\mathbf{V}}$ & 6 & $\begin{array}{l}\text { UWS 22, UWS 92, UWS 93, UWS 98, UWS 134, } \\
\text { JA -134 }\end{array}$ \\
\hline
\end{tabular}

Table.5 Average inter and intra- cluster distance $\left(\mathrm{D}=\boldsymbol{D}^{2}\right)$ values in $W$. somnifera

\begin{tabular}{|c|l|l|l|l|l|}
\hline Cluster & I & II & III & IV & V \\
\hline I & $\mathbf{1 3 . 8 5}$ & 25.84 & 26.66 & 27.41 & 33.37 \\
\hline II & & $\mathbf{1 0 3 . 8 1}$ & 13.97 & 12.21 & 10.83 \\
\hline III & & & $\mathbf{1 . 0 0}$ & 17.24 & 22.14 \\
\hline IV & & & & $\mathbf{2 8 . 8 3}$ & 15.31 \\
\hline V & & & & & $\mathbf{5 0 . 8 9}$ \\
\hline
\end{tabular}


Table.6 Cluster means and average (overall) for various characters in 25 genotypes of W. somnifera (L.) Dunal

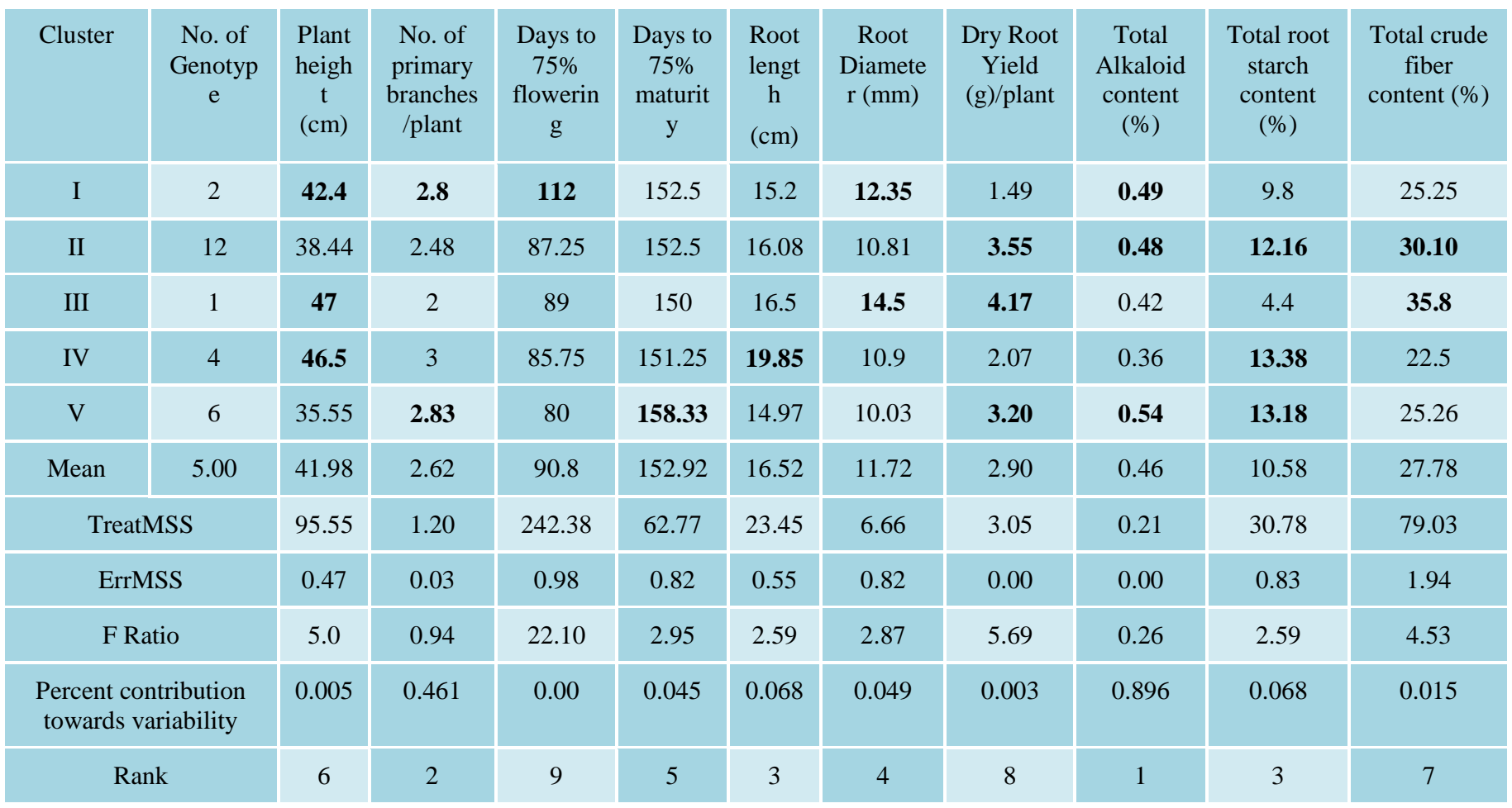

Fig.1 Intra and inter cluster distance for 5 groups of the 25 genotypes of $W$. somnifera

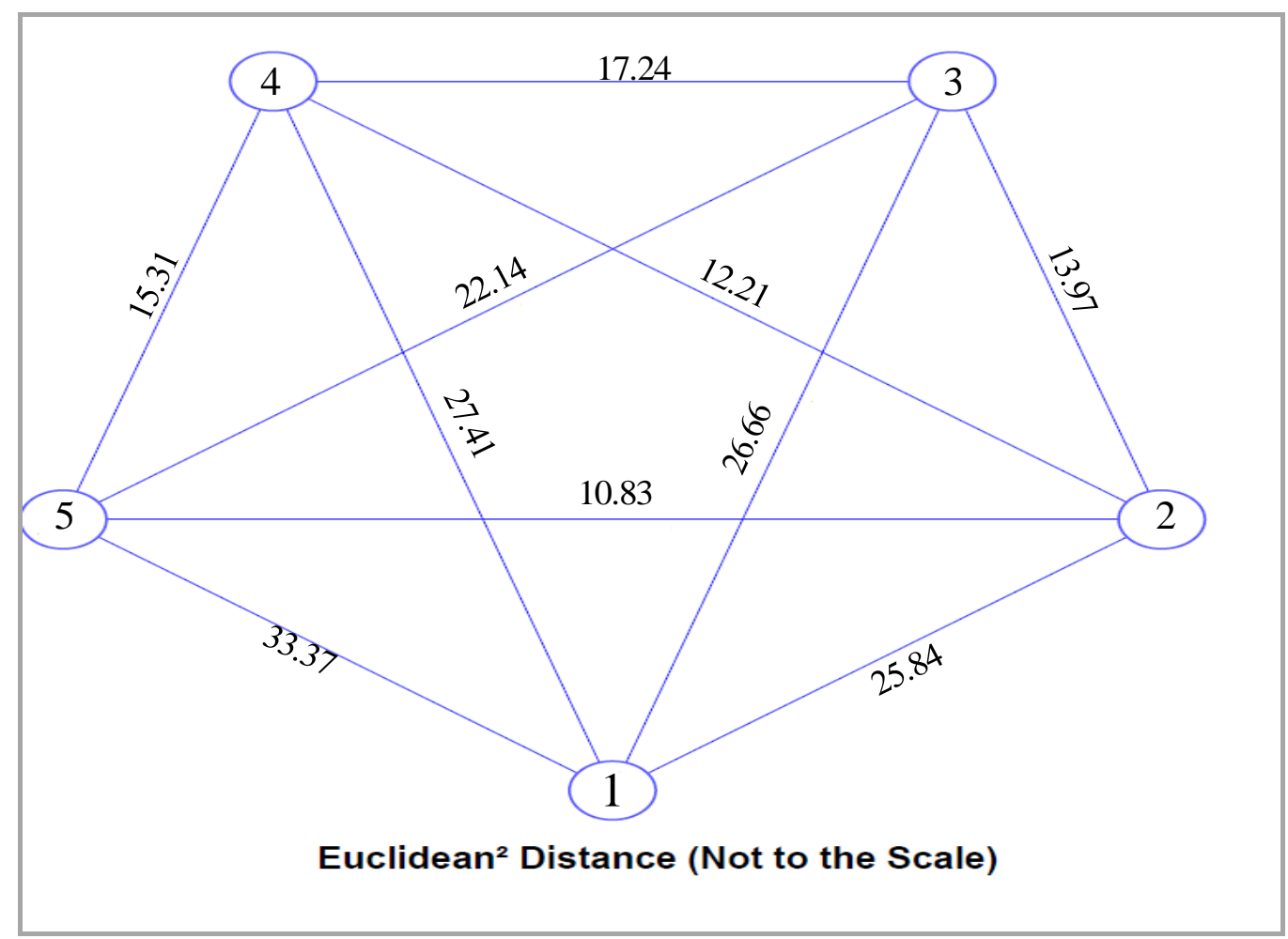


Fig.2 Dendogram based on Ward's minimum variance cluster analysis for the 25 genotype of $W$. somnifera

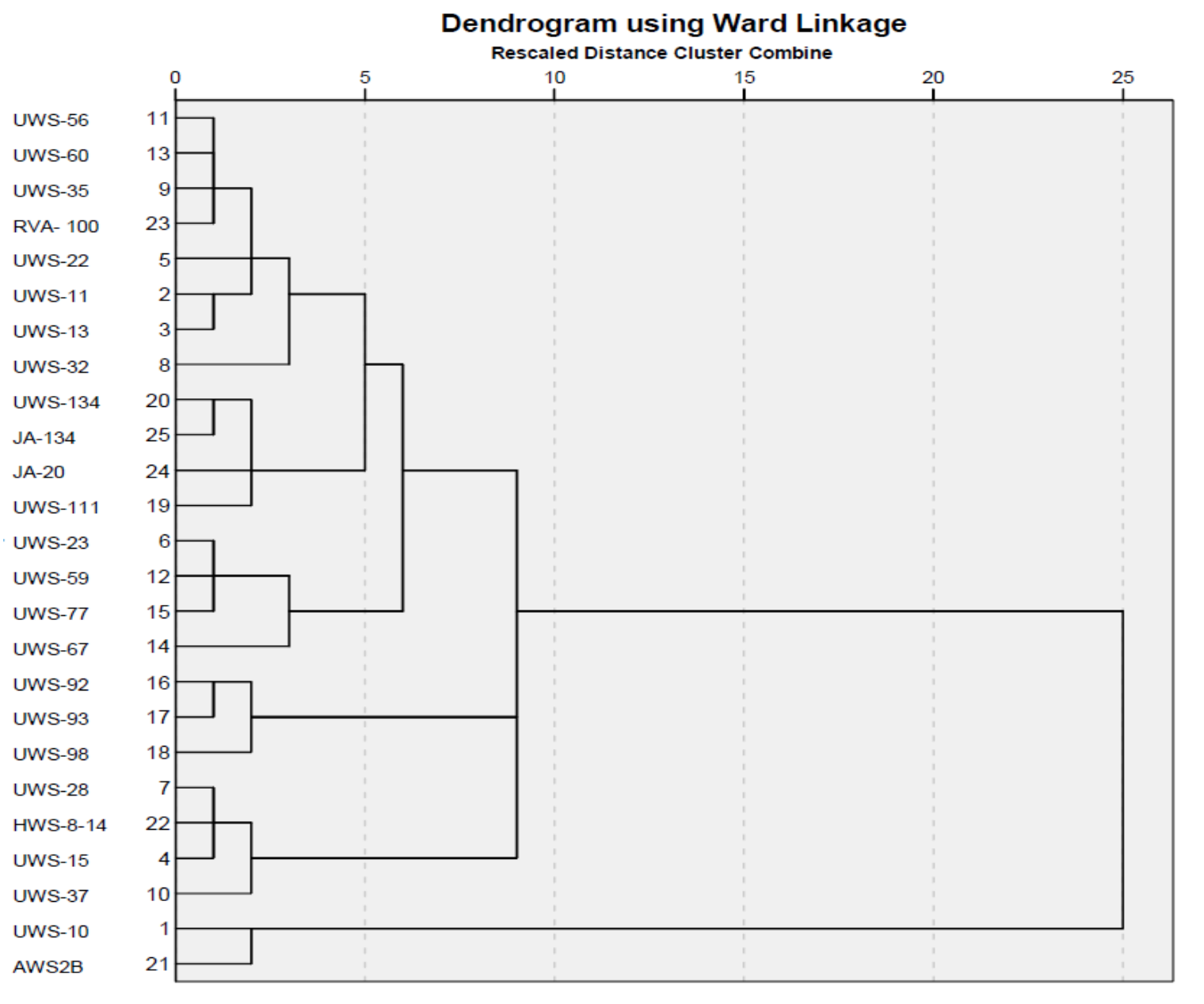

In this study, the highest inter-cluster distance was noted between clusters I and V (33.37) followed by cluster I and IV (27.41), III and I (26.66), I and II (25.84), V and III (22.14) and so on. The genotypes grouped in these clusters are found to be diverse. The least (10.83) inter-cluster distance was observed for cluster II and V followed by (12.21) intercluster distance between II and IV, thereby indicating their genetic relatedness. The average intra-cluster distance between the genotypes was maximum (103.81) for the cluster II followed in descending order by cluster V (50.89), IV (28.83), I (13.85) and III (1.0), respectively. Inter-cluster distances were greater than intra-cluster distances, showing a considerable degree of genetic diversity among the genotypes studied. Genotypes belonging to clusters with maximum inter-cluster distance are genetically more divergent and hybridization between genotypes in divergent clusters is likely to produce wide variability with desirable segregant (Maloo and Bhattacharjee, 1999).

Cluster mean for 10 characters for $25 \mathrm{~W}$. somnifera (L.) Dunal genotypes are presented in Table 5 which revealed that differences in cluster means existed for all the characters studied. The cluster I comprising 2 genotypes was found to have above average values for 
plant height, number of primary branches per plant, days to $75 \%$ flowering, root diameter and total alkaloid content. Cluster II had 12 genotypes that indicated above average values for dry root yield/plant, total alkaloid content, total starch content and total crude fibre content. Cluster III comprised of 1 genotype that was found to have above average value for plant height, root diameter, dry root yield/plant and total crude fibre content. Cluster IV consisted of 4 genotypes that showed higher than average value for plant height, root length and total starch content. Cluster V had 6 genotypes that exhibited over average values for number of primary branches per plant, days to $75 \%$ maturity, dry root yield per plant, total alkaloid content and total starch content. Results indicate that genotypes belonging to Cluster V viz., UWS 22, UWS-92,UWS-93, UWS-98,UWS-134 and JA-134 showed above average values for number of primary branches per plant, days to $75 \%$ maturity, dry root yield per plant, total alkaloid content and total starch content indicating their good potential for enhancing crop productivity. The percent contribution towards total genetic divergence was maximum for the character total alkaloid content followed by no. of primary branches per plant, root length and total starch content.

Ward's hierarchical cluster analysis was carried out on the basis of 10 morphological characters, employed to measure genetic distances between the $25 \mathrm{~W}$. somnifera (L.) Dunal genotypes (Figure 2). Cluster analysis revealed that the genotypes could be grouped into two clusters, cluster I and II that were apart at 25 rescaled values.

Cluster I included 23 genotypes viz., UWS 56,UWS 60,UWS 35,RVA100, UWS 22,UWS 11,UWS 13,UWS 32,UWS 134,JA134,JA-20,UWS 111,UWS 23,UWS 59,UWS 77,UWS 67,UWS 92,UWS93,UWS 98,UWS 28,HWS-8-14, UWS 15 and UWS 37. It could further be divided into 3 subclusters. Subcluster $I$ at 6 rescaled distances that included 12 genotypes viz., UWS 56, UWS 60, UWS 35, RVA 100, UWS 22, UWS 11, UWS 13, UWS 32, UWS 134, JA-134, JA-20 and UWS 111. It could be further subgrouped into 2 subgroups: Subgroup A and Subgroup $\mathrm{B}$, both at 3 rescaled distances, respectively. Subgroup A can be further divided into subgroup A1 and Subgroup A2. Subgroup A1 at 3 rescaled distances accounted for a small group of 7 genotypes viz., UWS-56, UWS-60, UWS-35, RVA-100, UWS-22, UWS-11 and UWS-13 and a single genotype viz., UWS-32. Subgroup B consists of 4 genotypes viz., UWS-134, JA-134, JA-20 and UWS-111. Subcluster II at 3 rescaled distance consisted of 3 genotypes viz., UWS-23, UWS 59 and UWS 77. Subcluster III at 3 rescaled distances consists of 4 genotypes viz., UWS28, HWS-8-14, UWS-15 and UWS-37. Cluster II included 2 genotypes viz., UWS-10 and AWS-2B at 3 rescaled distance.

This study will help plant breeders to identify, characterize and select authenticated genotypes in future crop improvement programmes, as a result, these genotypes will find commercial importance in their genetic content and medicinal value.

\section{Acknowledgements}

The authors gratefully acknowledge the financial assistance received from the RKVY project "Validation of important crop varieties through DNA fingerprinting towards conducting this research work.

\section{References}

Biennial Progress Report. 2006-08. Proceeding of Seventeenth Group Meeting of All India Networking Research Project on Medicinal \&Aromatic Plants. NRC on Medicinal 
and Aromatic plant, held at KAU Trichur.pp:15-18.

Covello, M. Ciampa G. 1960. Paper chromotatography of Withania somnifera. Alkaloid Journal of Chromatography, 3:591-92.

Gupta, A. K., Verma, S. R., Gupta, M. M., Dharmendra Saikia, Verma, R. K. and Tripta Jhang 2011. Genetic diversity in germplasm collections of Withania somnifera for root and leaf alkaloids. Journal of Tropical Medicinal Plants, 12 (1): 59-69.

Jain, S. K., Bordia, P. C. and Joshi, A. 2007. Genetic diversity in ashwagandha (Withania somnifera). Journal of Medicinal and Aromatic Plant Sciences, 29: 11-15

Joshi, N.R., Patel, M.A., Prajapati, K.N., Patel, J.R., Patel, A.D. 2015. Genetic diversity in ashwagandha (Withania somnifera (L.) Dunal). Electronic Journal of Plant Breeding 3:870-874.

Kumar, A., Kaul, M.K., Bhan, M.K., Khanna, K. Punit. and Suri, K.A. 2007. Morphological and chemical variations in 25 collections of the Indian medicinal plant, Withania somnifera (L.) Dunal. Genetic Resources and Crop Evolution, 54:655-660.

Mahalanobis P.C. 1936. On the generalized distance in Statistics. Proceeding of National Academy of Science, 2:49-55.

Maloo, S. R. and Bhattacharjee, I. 1999. Genetic divergence in foxtail millet. Recent advances in management of arid ecosystem proceedings of a symposium held in India. March, 1997, pp. 155158.

Mir, B. A., Koul, S., Soodan, A. S. 2013. Reproductive biology of Withania ashwagandha sp. novo (Solanaceae). Industrial Crops and Products, 45: 442-446.

Mishra, H. O., Sharma, J. R., Lal R. K. and Sharma, S. 1998. Genetic variability \& path analysis in ashwagandha (Withania somnifera). Journal of Medicinal \& Aromatic Plant Sciences, 20 (3):753756.

Nigam, K.B., Kandalkar, V.S. 1995. Ashwagandha - Advances in Horticulture, Medicinal and Aromatic plants. Malhorta Publishing House, New Dheli, India. 11: 337-344.

Singh G, Sharma PK, Dudhe R, Singh S. 2010. Biological activities of Withania somnifera. Scholars Research Library, 1:56e63.

Singh S, Kumar S.1998. Withania somnifera. The Indian Ginseng ashwagandha. Lucknow, India: Central Institute of Medicinal and Aromatic Plants.

Singh, A., Tirkey, A., Nagvanshi Disha. 2014. Study of Genetic Divergence in ashwagandha (Withania somnifera (L.) Dunal). International Journal of Basic and Applied science, 2(1):5-11.

Tuli, R. and Sangwan, R. S. 2009. "Ashwagandha (Withania somnifera)a model Indian medicinal plant". Council of Scientific and Industrial Research (CSIR), New Delhi.

\section{How to cite this article:}

Surya Chauhan, Arunabh Joshi, G. Rajamani and Devendra Jain. 2018. Genetic Diversity Analysis in Ashwagandha [Withania somnifera (L.) Dunal] Genotypes. Int.J.Curr.Microbiol.App.Sci. 7(01): 1574-1583. doi: https://doi.org/10.20546/ijcmas.2018.701.191 